\title{
10 health stories that mattered: May 31-Jun.6
}

- A third fewer people admitted to hospital for stroke die than a decade ago, but more people under age 70 are having strokes, states a report from the Heart and Stroke Foundation. Over the past 10 years, strokes in people in their 50s have increased $24 \%$, and have risen $13 \%$ for Canadians in their 60s.

- Of the 2.9 million inpatient hospitalizations in 2012-13, hospital stays for giving birth (369 454) outnumbered other reasons by a large margin. They were followed by respiratory disease (76 705), heart attack (68 835), pneumonia (60 077) and heart failure (56 260), reports the Canadian Institute for Health Information. The top inpatient surgeries were cesarean section (100686), knee replacement (57 829), hip replacement (47 297), hysterectomy (40 127) and coronary artery angioplasty (40 074).

- Canadians should not wait two or three times longer for medical care than people in other countries with universal health care systems, states a report from the Wait Time Alliance. Though several provinces (Ontario, Saskatchewan, and Newfoundland and Labrador) have made progress in reducing wait times in some areas, others struggled to "make any sustained improvements over the past three to four years."
- More than 1500 homes have radon levels exceeding government guidelines (200 becquerels per cubic metre), according to Health Canada data obtained by CBC News. The four hotspots for radon, which is the second-leading cause of lung cancer, are Manitoba, New Brunswick, Saskatchewan and the Yukon.

- Health Canada is struggling to process the 25 applications for medical marijuana licences it is receiving, on average, each week. By May, the department had received more than 850 applications, though only 13 have so far received licences.

- Despite accounting for $42 \%$ of Ontario's budget, health care was barely mentioned during a debate between Ontario leaders vying to win the upcoming provincial election. The scant discussion of health care, mentioned only in passing, prompted Health Minister Deb Matthews to tweet "What the heck? NO health questions????"

- Nine cases of salmonella infection - six in British Columbia, two in Quebec and one in Alberta - have been linked to the consumption of a sprouted chia seed powder. There has been one hospitalization, but no deaths. Health Canada has issued a recall for several products containing sprouted chia seeds.
- Ontario's privacy commissioner is seeking a court order against the Toronto Police Service for releasing mental health information to a national police database, reports the Toronto Star. According to the notice for application for judicial review, the police automatically disclose suicide attempts to the Canadian Police Information Centre database in breach of the Municipal Freedom of Information and Protection of Privacy Act.

- Quebec's new government has released a belt-tightening budget, but there will be no cuts to health services, according to Health Minister Gaetan Barrette. All health programs will undergo review, however, and the government is planning to table a bill that would allow it to apply staffing freezes in the health sector.

- Users of illicit drugs should be wary of unknowingly ingesting fentanyl when under the impression they are taking heroin or oxycodone, warns the Coroners Service of British Columbia. Fentanyl is particularly toxic, the statement warns, and has been involved in at least 13 deaths in the Fraser Region in the first four months of 2014 (compared to 12 in all of 2013 and six in 2012). Roger Collier, CMAJ

CMAJ 2014. DOI:10.1503/cmaj.109-4828 